\title{
A vingança do abjeto: erotismo e horror
}

\author{
Bárbara de Barros Fonseca \\ Mestranda em filosofia pela Universidade Federal Fluminense
}

Este curto ensaio visa apresentar brevemente uma tópica delineada como a vingança do abjeto. Sendo "abjeto" o que é ignominioso, vil, indigno e desprezível, pretendo fazer uma breve apresentação de como essa característica - que à primeira vista nos parece execrável e perniciosa para a filosofia - pôde ser enaltecida e abarcada pela mesma, além de ter seu lugar em outros domínios, como a psicanálise e a própria literatura.

Quando pensamos na estética clássica, vemos que o abjeto é desprovido de lugar enquanto uma qualidade a ser prezada numa obra. Logo, todas as obras que apresentam um teor "abjeto", que são obscenas, possuem conteúdo repugnante e retratam cenas que são asquerosas para um determinado gosto estético e que, principalmente, não tem essa temática como principal, são repudiadas e tidas como "literatura baixa", sendo banidas do panteão literário clássico.

Todavia, obras como as do Marquês de Sade - que eram banidas por sua imoralidade e obscenidade - e de H.P Lovecraft - que eram tidas como simples literatura pulp, sem qualquer grandiosidade por se tratar de contos de horror -, tiveram seu valor estético resgatado pela filosofia contemporânea, justamente por elas representarem - dentro mesmo de seu teor abjeto características importantes para a compreensão da condição humana.

Uma questão importante a se levantar é a espécie de indescritibilidade do abjeto, tanto no breviário pornográfico de Sade quanto nas aberrações cósmicas e ancestrais de Lovecraft, ambas se mostrando para nós como uma afronta a nossa racionalidade. Essa relação dúbia que mantemos com o "abjeto", entendido por Bataille como a dupla ordem de sedução ${ }^{1}$, em que ao mesmo tempo em que um objeto/situação é tido com ojeriza pelas pessoas, ele desponta uma sensação de curiosidade

\footnotetext{
${ }^{1}$ Bataille esquematiza a dinâmica das duas ordens de sedução nos seus textos escritos para a revista Documents, figurando principalmente em Le gros orteil e em Le langage des fleurs.
} 
e desejo nelas, evidenciando essa presença do abjeto em cada um, como "a parte obscura de nós mesmos"2.

Como são autores um tanto distintos em suas temáticas - e não nos delongaremos em uma abordagem muito extensa - , começaremos pela relação do abjeto e do sujeito na obra do Marquês de Sade, para depois tratarmos do abjeto no horror cósmico de Lovecraft.

Marquês de Sade é até hoje conhecido como um "maldito", tanto por sua vida conturbada e pervertida, como por sua obra, um breviário de horrores e perversões sexuais. Contudo, como já mencionamos, sua obra foi "recuperada" no século passado, tanto pela filosofia, com os trabalhos de Michel Foucault, Georges Bataille, Pierre Klossowski e Maurice Blanchot, como pela psicanálise, com Jacques Lacan.

Indagamos então, como um maldito, que teve sua literatura banida durante sua vida, conseguiu galgar um lugar dentro da análise filosófica. Como diz Roudinesco, podemos apreender que "o gozo do mal, não passava da expressão inerente ao próprio homem: a inumanidade do homem podia então ser vista como consubstancial a sua humanidade (...) (ROUDINESCO, 2008, p.44), o que vai contra toda uma metafísica clássica e cristã. O ideal libertino de Sade, em que o prazer e a vontade de destruir o outro e a si mesmo ocupam o patamar mais alto, é baseado em uma concepção de natureza que demanda a destruição para a sua renovação e a sua movimentação energética. Assim, essa violenta ebulição da natureza é espelhada no comportamento humano que caso o sujeito coadune com esse materialismo baseado no nosso abandono pela natureza no mundo - age de acordo com o egoísmo e a busca do prazer próprio, respeitando os princípios da própria natureza.

A partir desta concepção de natureza - que já é por si só muito interessante para o pensamento filosófico - Sade enfatiza que é a volúpia que alenta nossa solidão no mundo, e o que o libertino faz é justamente superar esse desamparo a partir da exploração dos prazeres do corpo.

\footnotetext{
${ }^{2}$ Referência ao título do livro de Élisabeth Roudinesco, "A parte obscura de nós mesmos", no qual ela aborda questões como a perversão e em que ela dedica um capítulo ao estudo da obra de Sade.
} 
Como diz Eliane Robert Moraes, "a escrita de Sade visa, em última instância, tocar na singularidade de cada um de nós." (MORAES, 2011, p.23).

O "exagero" provocado pela "escola de libertinagem" de Sade, onde as posições sexuais e as práticas de tortura praticamente escapam à compreensão com suas enormes "cifras do gozo", provocam essa estupefação, como uma mescla de nojo e de atração, em que às vezes chegamos a identificar-nos com os prazeres retratados, o que desnuda a "sujeira" presente em todos nós.

A concepção materialista que Sade possui, onde o sujeito representa um papel de engrenagem da natureza que se engaja na destruição que dela é motor, é crucial para o desenvolvimento de um pensamento que "destrona" o ser humano de seu privilégio ontológico.

Por mais que o sujeito sadeano seja soberano, como propõe Bataille ${ }^{3}$, ele é preso em sua soberania, que é a de buscar sempre o gozo maior. Porém, ele não é submisso a nenhuma ordem divina ou classificação inerente da natureza que o torne ontologicamente superior a outro, e o próprio movimento de soberania, que culmina na anulação do outro e na anulação de si mesmo devido à procura por esse "gozo e crime maior" demonstram isso.

A natureza materialista que se renova a partir da destruição entende o ser como imanente, que comete o crime enquanto um modo da natureza, e que não pode ser submetido a nenhuma moral artificial. O modo soberano do sujeito sadeano é pautado numa inversão radical da lei, que entende o corpo como fadado à morte, e por isso se delicia na volúpia do crime e dos prazeres pautados num compêndio da desconstrução corporal.

Sade faz, de tal modo, uma conexão entre o abjeto e o excesso em que, a partir dessa desordem erótica, se desenvolve o paroxismo da soberania do homem sadeano, no qual percebemos uma dinâmica entre negação e afirmação, uma fissura do sujeito que, a partir da proficuidade do excesso, culminará no movimento de afirmação do homem a partir da negação do outro, desembocando na negação de si próprio como maior possibilidade do prazer e pelo movimento do crime que ultrapassa o sujeito.

\footnotetext{
${ }^{3}$ Bataille desenvolve essa relação entre Sade e a soberania no livro "O Erotismo", no qual ele defende a ideia de que o homem sadeano enfrenta o paradoxo da soberania, onde não pode se submeter a nada que não seja um gozo maior, o que culmina na aniquilação do outro e na aniquilação de si mesmo. (BATAILLE, 2013, p. 191-203)
} 
A volúpia é um fim em si mesma, e ultrapassa os limites da utilidade humana. Assim, na formulação da soberania do sujeito, tem-se o fato de que homem verdadeiro sabe que é só e, portanto, realiza a operação de negar o que se refere a outros que não ele, resultando nessa afirmação de si a partir da negação do outro, onde - a princípio - a satisfação de seu desejo é norteadora

O esvaziamento da sensibilidade por conta de uma maximização do prazer é a causa da soberana apatia do homem sadeano. Sade se dá conta de que a espontaneidade da paixão não possibilita a maior jouissance do prazer, e por isso a insensibilidade seria a única capaz de realizar a maior paixão possível, visto que a alma esvaziada se identifica à mais completa destruição que será consumada.

Quanto a essa destruição, podemos compreender como a volúpia e o crime terão uma íntima relação, pois o crime vai além da importância da luxúria e é o signo do caráter excessivo que transgride o próprio ser com o advento da insensibilidade, a partir da apatia. É nisso que se constitui a "prisão" do homem soberano, que não consegue escapar da movimentação de sua própria crueldade, na qual a negação o ultrapassa.

Justamente a ilimitação dos "poderes" soberanos do homem de Sade o encaminham para essa negação de si próprio, visto que o homem se torna vítima de sua própria soberania por não poder se submeter a nada que não seja esse gozo maior, pois ele não é livre para se submeter. Logo, essa impossibilidade de se submeter leva à negação ilimitada do outro que, extremizada, é negação de si.

De tal modo, esse ser soberano pode ser compreendido neste jogar-se no excesso do seu próprio ser, no qual o dispêndio inútil e o abjeto são o único manancial de felicidade. O ponto mais alto dessa felicidade é o apogeu da transgressão, em que crime e luxúria se tornam irmãos. Esse excesso extremo, que tudo excede com a negação dos outros, se torna negação de si mesmo pela movimentação que supera o ser pessoal, conduzindo a passagem do egoísmo à vontade de ser consumido pelo movimento da transgressão.

Finalmente, após essa breve explanação da negação do sujeito em Sade que ocorre através do excesso e da imersão no domínio abjeto da volúpia e do crime, podemos entrever a maneira como Sade dessacraliza o homem e posiciona o abjeto em nosso cerne, indo contra toda uma metafísica 
que enaltecia a figura humana como imagem e semelhança de Deus, ao destacar a perversão e o gosto pelo abjeto que jaz em cada um de nós.

O abjeto faz parte da condição humana, e, segundo o excesso sadiano que reflete a centelha de perversão que há em todos nós, "para ser verdadeiramente feliz nesse mundo, um homem somente havia de se entregar a todos os vícios, sem nunca se permitir virtude alguma, pois não se tratava apenas de fazer o mal, como também de nunca fazer o bem." (SADE, 2013, p.20)

Agora, com uma mudança de gênero que parte do erotismo para o horror, vamos tentar abordar o que seria o abjeto dentro da obra de H.P Lovecraft. De maneira um pouco semelhante, Lovecraft também não chegou a ver o valor que sua obra teria durante sua vida. Foi tido, em sua época, como escritor menor, que publicou em revistas e sofria com o preconceito acadêmico em relação ao gênero de horror/ficção científica, compreendidos como mera literatura pulp.

A importância do abjeto aqui é de um âmbito mais amplo que o de Sade, que, por mais que questione a condição humana e mostre as fissuras do sujeito, não chega a formular um questionamento forte ao antropocentrismo. Já em Lovecraft, a dimensão cósmica e ancestral de seres, eventos e formações que escapam totalmente ao nosso entendimento, e que nós apenas conseguimos apreender com espanto ou ojeriza, temos que o abjeto cósmico mostra a nossa pequenez e finitude frente a um universo caótico que não tem a menor apreciação pela nossa espécie.

Essa crítica ao antropocentrismo se torna evidente em sua própria forma de escrita. Lovecraft transmite a incapacidade de tradução da realidade em palavras na vasta maioria de seus contos, como quando tenta explicar a aparência de Cthulhu em "O chamado de Cthulhu"4, ou as estruturas

\footnotetext{
4 "The Thing cannot be described - there is no language for such abysms of shrieking and immemorial lunacy, such eldritch contradictions of all matter, force and cosmic order." (LOVECRAFT, 2011, p. 377)
} 
ciclópicas na Antártida de "Nas montanhas da loucura"5 , e também quando tenta tornar plausível a imagem da "Cor que caiu do espaço" 6 .

De tal modo, Graham Harman conclui que

the meaning of being might even be defined as untranslability. Language (and everything else) is obliged to become an art of allusion or indirect speech, a metaphorical bond with a reality that cannot possibly made present. (HARMAN, 2012, p.16)

Essa forma estaria presente em toda prosa de Lovecraft, já que "Lovecraft's prose generates a gap between reality and its accessibility to us". (HARMAN, 2012, p.28)

Logo, nos contos de Lovecraft temos contato com o que há de mais exterior e estranho ao homem, com formulações e sujeitos que antecedem a humanidade em éons, e que respeitam leis físicas e materiais às quais nós desconhecemos completamente, que permitem uma conexão entre os multiversos através dos fatores do mundo onírico (onde nos comunicamos com as raças primordiais), da geometria espacial (que permite viagens temporais e transmudanas a partir da geometria não-euclidiana e da física mais avançada que há) e do vetor temporal (numa temporalidade que não responde à continuidade clássica da física moderna).

De acordo com a leitura de Fábian Ludueña, Lovecraft efetua uma operação de reviver o mito. Todavia, o mito que é revivido por Lovecraft é totalmente distinto dos nossos mitos fundadores, em que a nossa humanidade é sempre salvaguardada pelas entidades superiores, e nós somos importantes dentro da ordem cósmica.

Já em Lovecraft, constatamos uma mitologia - que permeia todos os seus contos onde os personagens são intercambiados, como os Primordiais, Cthulhu, Azathoth, etc - e que são raças cósmicas que não cultivam o menor cuidado pela humanidade. Assim, com sua concepção de universo infinito, o mito não é antropomórfico, e o cosmos funciona sem a menor dependência da humanidade, visto que a inexistência dos humanos não mudaria nada na ordem do universo.

\footnotetext{
5 "Even the pictures illustrate only one or two phases of its infinite bizarrerie, endless variety, preternatural massiveness, and utterly alien exoticism. There were geometrical forms for which an Euclid could scarcely find a name (...). (LOVECRAFT, 2011, p.762)

6 "It was just a colour out of space - a frightful messenger from unformed realms of infinity beyond all Nature as we know it; from realms whose mere existence stuns the brain and numbs us with the black extra-cosmic gulfs it throws open before our frenzied eyes." (LOVECRAFT, 2011, p.616)
} 
O abjeto que é percebido por nós nos seres e estruturas antepassados, com sua arquitetura de cidades ciclópicas e seres que transbordam nossa capacidade de categorização e compreensão e que não respeitam as nossas leis clássicas da mecânica e da geometria, suscitam a apreensão e o medo frente ao abjeto.

Desta maneira, o horror frente ao abjeto que escapa ao antropomorfismo impede um maravilhamento em relação ao mito, diferentemente da nossa relação com os mitos antropomórficos, visto que, o mito proposto por Lovecraft finda na aniquilação do homem, que é definido por forças avassaladoras.

Com seu materialismo cosmológico, percebemos a insignificância do homem frente aos mundos transfinitos e as anciãs raças cósmicas, que detiveram o poder no passado e o detêm ainda hoje. Assim, segundo Ludueña, Lovecraft

postula uma filologia que não é a ciência do homem, e sim do cosmos infra e supra-humano. Os documentos e os monumentos que o homem encontra não são senão a prova de sua insignificância ontológica. (LUDUEÑA, 2013, p.29)

Constatamos a queda do humanismo a partir do mito Lovecraftiano, no qual o universo é absolutamente infinito e o espaço abriga a destruição da humanidade. O cosmos desponta como, ao invés de a doce morada da humanidade, a fonte de aniquilação da espécie humana, na qual o homem descobre seu não-lugar antrópico.

A partir dessa queda frente ao abjeto - que nos é abjeto por ser indescritível e totalmente outro -, na qual o abjeto representa uma verdade e uma existência completamente anterior ao homem, podemos pensar na relação entre a cosmologia existente na obra de Lovecraft e na teoria do sujeito. Como já vimos, a relação peculiar do sujeito frente ao cosmos que lhe escapa à compreensão denota essa pequeneza humana frente ao cosmos, visto que não compreendemos as lacunas apresentadas entre os objetos e suas qualidades, que não se enquadram em nossas categorias antropocêntricas do conhecimento.

Todas essas características presentes nos contos de Lovecraft são de crucial importância para o pensamento filosófico em relação tanto à epistemologia quanto à teoria do sujeito. Como diz 
Ludueña, "Lovecraft, através do Mito, recorda que pensar o universo e sua constituição ainda pode ser tarefa da filosofia". (LUDUEÑA, 2013, p.40)

Pensando na preeminência ontológica de diversos seres em relação à humanidade, vemos que a subjetividade não é de fato uma propriedade humana, ela vai além da linguagem, do tempo e do espaço. Temos assim uma abertura para pensar a filosofia além do orgânico e do inorgânico, já que o sujeito humano ocupa um papel totalmente marginal no cosmos. "A espécie humana e, a fortiori, a própria vida em suas formas biológicas conhecidas pelo homem não são necessárias para a existência do sujeito." (LUDUEÑA, 2013, p.46)

Lovecraft introduz, a partir de sua utilização da magia, matemática, física e artifícios oníricos em seus contos uma fenda no universo, que nos apresenta o horror frente ao desconhecido e ao abjeto. Nós ficamos com a indagação de: como pensar o sujeito no marco de um multiverso?

Por fim, podemos entender como o abjeto aparece na obra de Lovecraft como, além de inapreensível e indescritível pelo homem, como sendo superior ao humano, ancestral e poderoso. O antropocentrismo é totalmente rechaçado, assim como o antropomorfismo, que não resiste às representações cósmicas que escapam às leis físicas e matemáticas conhecidas pela humanidade. Ludueña diz que a "densidade no Ser que não pode ser apreendida segundo as tradicionais categorias da metafísica ou da ciência, e que demanda um novo esforço de captação." (LUDUEÑA, 2013, p.56)

Logo, o abjeto abre para nós tanto uma nova maneira de compreender a subjetivação, assim como para compreender um universo que em muito nos escapa, destronando todo o antropocentrismo legado pela tradição da modernidade.

Desta forma, ao evidenciar a atração realizada em nós por essas temáticas ignóbeis, podemos compreender o modo como o privilégio ontológico do humano entendido enquanto "imagem e semelhança de Deus" e "aspiração ao que há de belo e bom" é decaído, ao percebermos o que há de execrável em nós e a nossa pequeneza cósmica, para entendermos uma distinta valorização, agora 
do excesso que ultrapassa as nossas compreensões racionais. A vingança do abjeto traz uma diferente maneira de pensar a filosofia e o homem; e o erotismo e o horror, ao invés de exaltar a racionalidade, a harmonia e o sublime, insurgirão aqui como gêneros que questionarão a figura humana, onde esta se encontra em risco de sua dissolução. Desta maneira, concluímos que a figura humana não é exaltada, mas sim está sempre em perigo. A partir do horror cósmico e a insignificância frente ao caos do cosmos em Lovecraft, e da dissolução da individuação proporcionada pelo erotismo sadeano, vemos a conquista da vingança obtida pelo abjeto na (ou da) filosofia.

\section{Bibliografia:}

BATAILLE, G. Documents. Paris: Mercure de France, 1968.

BATAILLE, G. O Erotismo. Belo Horizonte: Autêntica, 2013.

HARMAN, G. Weird realism: Lovecraft and philosophy. Winchester: Zero Books, 2012.

LOVECRAFT, H.P. The Complete Fiction. New York: Barnes \& Noble, 2011.

LUDUEÑA, F. H.P. Lovecraft: A disjunção no ser. Florianópolis: Cultura e Barbárie, 2013.

MORAES, E. Lições de Sade - ensaios sobre a imaginação libertina. São Paulo: Iluminuras, 2011.

ROUDINESCO, E. A Parte obscura de nós mesmos: Uma história dos perversos. Rio de Janeiro: Zahar, 2008.

SADE, D. Os 120 dias de sodoma ou a escola da libertinagem. São Paulo: Iluminuras, 2013. 